\title{
EDUCAR PARA/NA TOLERÂNCIA: OS DESAFIOS DA ÉTICA DE MÍNIMOS Marcelo Andrade ${ }^{1}$ Departamento de Educação, PUC-Rio
}

\section{TOLERAR É POUCO?}

Muitas vezes escuto de diferentes pessoas afirmações do tipo: "Não gosto da palavra tolerância, falta-Ihe utopia, proposta" ou "Tolerância é uma atitude antipática, pois revela indiferença com o outro", ou ainda: "Parece atitude de gente que se sente superior e permite a presença do outro".

Muitos rejeitam o conceito de tolerância por considerar que ele representa "uma atitude neutra de quem não quer aceitar e muito menos amar o outro, mas apenas 'tolerar', permitir, como um favor de condescendência, que ele exista". (Menezes, 1997, p. 40).

Essas críticas geralmente se baseiam na idéia de que a tolerância é um valor menor no campo da ética e das relações sociais. Parecem crer que a tolerância é uma atitude simples demais, quase um favor que se faz ao outro, mas que na verdade não o aceita. Em resumo, acredita-se que tolerar é pouca coisa.

Assim, defendem atitudes éticas mais fortes, tais como: solidariedade, amor ao próximo, fraternidade, igualdade, respeito, compreensão, entre outras, e não apenas a tolerância, essa postura cheia de indiferença. Alega-se, nesse raciocínio, que no campo da ética devemos ser mais ousados, impulsionar projetos que nos mobilizem, que nos dêem sentidos mais amplos. Ou seja, reclama-se uma dimensão mais propositiva, ausente da temática da tolerância e, sendo assim, supostamente mais necessária do que ela.

Buscarei demonstrar nesta artigo que tolerar não é pouca coisa, ainda que assim pareça para muitos.

\section{MÁXIMAS E MÍNIMO: O BOM E O JUSTO.}

Pouco nos adiantaria ficar apenas lamentando sobre a incompreensão que ronda o conceito de tolerância. Considero que podemos - e na verdade,

\footnotetext{
${ }^{1}$ Licenciado em Filosofia, Mestre em Educação e Doutor em Ciências Humanas. Professor do Programa de Pós-Graduação em Educação da PUC-Rio.
} 
devemos - projetar valores e atitudes mais amplos, tais como: a fraternidade, o amor, a solidariedade entre os povos. No entanto, se quisermos ser mais realistas é imperativo que construamos estratégias que assegurem o mínimo moralmente exigível, ou seja, aquele pouco que nos revela o fundamental. E o que é fundamental, na verdade, não é pouco, é sim o mais importante. Aquilo que, num primeiro momento, parece pouco pode ser o fundamental, o imprescindível, aquilo que, em hipótese nenhuma, pode faltar.

É neste sentido que a filósofa espanhola Adela Cortina questiona-se sobre quais são os mínimos decentes de moralidade para serem respeitados para se comportar com justiça numa sociedade plural. Para a ela, quando falamos de "mínimos morais" estamos fundamentalmente diante de uma questão de justiça, ou seja, como atender, com equidade, as diferentes demandas e necessidades dos diferentes grupos de nossas sociedades pluralistas, multiculturais.

Cortina (1996, p. 57) situa esta árdua tarefa - "fixar um mínimo decente de valores partilhados, a fim de que as decisões sejam respeitosas da pluralidade" - nas definições sobre "éticas da justiça" e "éticas da felicidade". Segundo a autora, é importante distinguir no campo moral as distâncias e as aproximações entre o que é justo e o que é bom. Sem negar esta inter-relação entre o bom e o justo, a autora defende a delimitação dos conceitos. Argumenta que o justo tem a ver com o que é exigível e como tal se torna obrigação moral para qualquer ser racional que queira pensar e agir moralmente. "Donde podemos concluir que é moralmente justo aquilo que satisfaz aos interesses universalizáveis” (Cortina, 1997, p. 62).

O que é moralmente justo é necessário para todo ser racional que queira ser moral. Nesta perspectiva, necessário e universal significam obrigatório, aquilo que é exigível, que não é contingente. Por sua vez, o bom é aquilo que causa a felicidade, ou seja, autorrealização por alcançar os fins propostos, intencionalmente ou não. O bom não pode ser exigido dos outros seres racionais, pois se trata fundamentalmente de uma realização subjetiva, pessoal. O que é bom para um pode não ser bom para outro. O que causa felicidade a um pode não causar a outro. O bom, neste sentido, está no campo das possibilidades e nunca das exigências. 
As éticas de justiça ou éticas de mínimos ocupam-se unicamente da dimensão universalizável do fenômeno moral, isto é, daqueles deveres de justiça exigíveis de qualquer ser racional, e que, efetivamente, só são constituídos de exigências mínimas. Ao contrário, as éticas de felicidade pretendem oferecer ideais de uma vida digna e boa, ideais que se apresentam hierarquizadamente e englobam o conjunto de bens que os homens usufruem como fonte de maior felicidade possível. São, pois, éticas de máximas, que aconselham a seguir o modelo e convidam-nos a toma-los como norma de conduta, mas não podem exigir ser seguidos, visto que a felicidade é tema de aconselhamento e convite, e não de exigência. (Cortina, 1999, p. 62)

Não se quer aqui afirmar que as exigências mínimas sejam "melhores" que as máximas possíveis. Não quero deixar transparecer que fraternidade e igualdade representam ilusões que devam ser ignoradas por serem inocentes ou tolas demais, ao contrário, o que pretendo é defender que junto com os máximos - as grandes utopias humanas - devemos buscar uma agenda mínima de ação, que deve ser entendida como deveres de uma ética de justiça; e por isso mesmo exigível de qualquer ser racional que se pretenda moral. Aposto muito mais numa relação dialética entre o justo e o bom, o exigível e o possível, o mínimo e as máximas, do que numa oposição binária entre esses conceitos.

No entanto, insisto que não se pode exigir moralmente que nos amemos fraternalmente, porque "somos todos filhos de Deus" ou porque "somos todos iguais", pois essas máximas só podem funcionar como convites e aconselhamentos e nunca como uma exigência.

Então, melhor será construir estratégias que garantam a tolerância como um requisito mínimo - no sentido de ser fundamental, imprescindível - para a convivência humana. Por exemplo, onde não tem sido possível a igualdade e o amor fraterno para alcançarmos a paz e a concórdia, que seja pelo menos a tolerância. As propostas sobre a tolerância saem do campo do convite e a do aconselhamento - do qual concordo que não devemos abrir mão, pois a dimensão utópica é inerente ao ser humano - para encontrar algumas saídas moralmente exigíveis no âmbito do convívio social. 


\section{TOLERÂNCIA, UMA AGENDA MÍNIMA.}

Cumpre registrar que uma pergunta poderia ser agora levantada: é a tolerância o principal valor moral a ser apresentado como exigência mínima? Por que tolerância e não algum outro valor moral, como justiça ou a igualdade, por exemplo? Afinal, por que a tolerância como agenda mínima?! A essa questão respondo: porque a intolerância tornou-se uma prática comum diante da diferença.

Em sociedades multiculturais e marcadas pelo preconceito e pela discriminação de vários tipos, tais como: racismo, sexismo, xenofobia, homofobia, entre outros, a tolerância com o diferente apresenta-se como uma agenda mínima, urgente e extremamente necessária.

Segundo Augras (1997, p. 78), "quando se fala de tolerância é, na verdade, da intolerância que se trata”. O conceito de tolerância se coloca cada vez mais na pauta de discussão porque a intolerância com a diferença tem sido recorrente na história da humanidade e ainda hoje em nossas sociedades. Inegavelmente estamos caracterizados pela diferença e, no entanto, parece que não sabemos trata-la.

A humanidade - marcada dolorosamente pela escravidão dos negros, pelo genocídio dos povos ameríndios, pelo holocausto dos judeus, pela perseguição aos ciganos, pela submissão das mulheres e a negação de direitos aos homossexuais - busca não mais permitir nenhuma manifestação de intolerância com o diferente, pois "a intolerância não é apenas questão de não tolerar as opiniões divergentes; ela é agressiva e com freqüência assassina, no seu ódio à diversidade alheia”. (Menezes 1997, p. 46)

Menezes (1997, p. 41) afirma que o termo tolerância aparece pela primeira vez entre os iluministas. Foi Locke o primeiro a tratar explicitamente 0 tema na obra "Cartas sobre a tolerância", no século XVII. No século XVIII, foi a vez de Voltaire retomar o tema no célebre "Tratado sobre a tolerância". O nascimento do conceito se deu no rescaldo das lutas religiosas, dos massacres recíprocos de protestantes e católicos. Os livres-pensadores, adeptos do lluminismo, viam-se discriminados e perseguidos por todos os fanatismos. E foram eles que mobilizaram a opinião pública contra os horrores da intolerância, proclamando o sagrado direito de discordar. 
Na verdade a tolerância surgiu historicamente como uma luta contra a intolerância, e, como as lutas contra as discriminações que vieram depois - o movimento negro, o movimento feminista etc. - tem uma atitude clara de militância, não é uma atitude primeira. É, antes, uma reação contra uma situação dada; contra a intolerância; é a defesa de um direito humano dos mais sagrados; o direito à diferença. (Menezes, 1997, p. 42).

O conceito de tolerância surge como resposta contra a intolerância à diferença. Sendo assim, é fundamental que ao tratarmos de tolerância, pensemos na natureza, nas causas e nas conseqüências da intolerância. A intolerância não rejeita só as opiniões alheias, mas também sua existência, ou ao menos o que faz o que valha a pena viver: a dignidade e a liberdade da pessoa. A intolerância diante do diferente tem imposto uma quantidade de maus-tratos e massacres impiedosos a grupos que sustentam um estigma, um suposto sinal vergonhoso e socialmente rejeitado.

Eco (2001, p. 114), por sua vez, chama a atenção para a intolerância selvagem, sem nenhuma razão explícita ou doutrina que a sustente:

\footnotetext{
A intolerância coloca-se antes de qualquer doutrina. Nesse sentido, a intolerância tem raízes ideológicas, manifesta-se entre os animais como territorialidade, baseia-se em relações emotivas muitas vezes superficiais - não suportamos os que são diferentes de nós porque têm a pele de cor diferente, porque falam uma língua que não compreendemos, porque comem rãs, cães, macacos, porcos, alho, ou porque se fazem tatuar...
}

Alguns estudiosos ocupam-se com freqüência das doutrinas da diferença, mas não o suficiente da intolerância selvagem, pois esta foge de qualquer possibilidade de discussão e de crítica, pois não está colocada num nível racional, mas no nível visceral $\mathrm{A}$ intolerância é, em geral, raivosa, descontrolada, inexplicável e impulsiva.

A intolerância é um desafio atual e urgente. O nosso tempo marcado por terrorismos e guerras, por espancamento de homossexuais e mulheres está aí para não nos deixar esquecer a grandeza e complexidade do que temos que enfrentar. A intolerância, como outras urgências de nosso mundo, é também um desafio para a educação. O tema, assim, nos impulsiona a pensar a relação entre educação e ética. 


\title{
EDUCAR PARA/NA TOLERÂNCIA.
}

Nesta reflexão sobre as articulações entre educação e ética mínima, cumpre relembrar mais uma vez a urgência do tema em nossos dias.

\begin{abstract}
Educar para tolerância adultos que atiram uns nos outros por motivos étnicos e religiosos é tempo perdido. Tarde demais. A intolerância selvagem deve ser, portanto, combatida em suas raízes, através de uma educação constante que tem início na mais tenra infância, antes que possa ser escrita em um livro, e antes que se torne uma casca comportamental espessa e dura demais. (Eco, 2001, p.117)
\end{abstract}

A questão, então, é sobre como se aprende um valor moral. Charlot (2000, p. 68-70) nos oferece uma importante contribuição nesta perspectiva ao definir as "figuras do aprender". Para o autor, o aprender pode significar três dimensões distintas: (1) "apropriar-se de um conteúdo"; (2) "dominar uma atividade" e (3) "entrar num dispositivo relacional".

A primeira figura diz respeito aos conteúdos intelectuais que o sujeito se apropria, inculca, toma posse. Esses conteúdos estão depositados em pessoas (professores, pais etc), objetos (livros, revistas etc) e locais (escola, museus etc). A segunda figura diz respeito a passar de um não domínio ao domínio de uma atividade, por exemplo: nadar ou amarrar os cadarços do tênis. Este domínio, em geral, se inscreve no corpo e o resultado do aprendizado é a própria atividade a ser aprendida. A terceira figura do aprender é o que melhor nos serve para entender os fundamentos de uma educação moral. Para Charlot (2000), aprender também significa entrar em relação com o mundo, com os outros e consigo mesmo. A terceira figura não exclui as duas primeiras, ou seja, inclui apropriar-se de conteúdos e passar do não domínio para o domínio. No entanto, tratar-se-ia agora de conteúdos morais ou éticos (e não mais conteúdos objetivos) e do domínio de uma relação consigo e/ou com os outros (e não mais de uma atividade). Essa "entrada numa relação intersubjetiva" pode passar pelo âmbito da reflexão e ser posteriormente substancializada. Assim, poder-se-ia dizer que através de determinadas relações aprendemos a solidariedade, a confiança, o amor próprio ou, como buscamos em nosso argumento, a tolerância.

Tendo em vista a urgência e a possibilidade de se aprender a tolerância, considero fundamental ainda nesta reflexão é a necessidade de pensar, no 
campo educacional, sobre quais são os valores fundamentais, imprescindíveis a serem ensinados.

Os educadores também têm de saber quais são seus 'mínimos decentes' de moralidade na hora de transmitir os valores, sobretudo no que diz respeito à educação pública numa sociedade pluralista. Pois é certo que, por serem educadores, não tem legitimidade para transmitir, sem mais, apenas os valores que lhes pareçam oportunos. (...) Não seria urgente descobrir quais são os valores que podemos partilhar e que vale a pena ensinar? É ou não é urgente descobrir um 'mínimo decente de valores' já partilhados? (Cortina, 1997, p. 57-58).

Se concordarmos com a filósofa espanhola que é fundamental pensarmos num conjunto mínimo de valores a ser ensinado numa sociedade pluralista a fim de se respeitar a diversidade, então, cabe-nos mais uma vez justificar a opção pela tolerância como agenda mínima, agora no campo educacional propriamente dito.

E aqui apresento o último ponto desta a defesa sobre uma educação para a tolerância. Educar nesta perspectiva diz mais respeito ao que não se deve fazer do que ao que se deve sentir, pois buscamos um valor mínimo exigível, no âmbito da ética de justiça, que busca regular atitudes. Que fique claro: devido a uma opção respeitosa da diferença, não estamos buscamos um conjunto de máximas aconselháveis, convites de uma ética de felicidade, mas mínimos éticos, exigíveis, reguladores de atitudes, de comportamentos.

Aqui encontramos um ponto fundamental em defesa da tolerância, da ética dos mínimos e, de certa forma, da dimensão proibitiva no campo da ética, que alguns teóricos preferem chamá-la de dimensão moral. (La Taille, 2002)

A dimensão propositiva da ética, e conseqüentemente os projetos educativos que daí derivam, buscam legislar sentimentos, tais como: amar ao próximo, aceitar o outro, valorizar a paz e a fraternidade. Máximas de convite e aconselhamento, como já visto anteriormente. A dimensão proibitiva legisla atitudes: não roubar, não matar, não mentir. Âmbito de uma ética de justiça, minimamente exigível e reguladora de comportamentos.

É óbvio que as normas proibitivas podem ser ditas como assertivas, tais como: dizer a verdade, respeitar a vida, respeitar o que pertence ao outro. Porém, parece-nos que a formulação na negativa tem sido historicamente consolidada por ser mais clara, direta, objetiva. E em tempos de crise ética, 
como os nossos, na qual a dúvida entre o que é certo e o que é errado se faz crescente, acho preferível optar sempre por formulações que não permitam ambigüidades.

Não se pretende aqui, de maneira nenhuma, oferecer receitas, mas apenas destacar como um argumento pode dar ênfase nas normas propositivas, que buscam legislar sentimentos e como outro argumento pode dar ênfase nas normas proibitivas, que buscam acordar atitudes.

Uma estratégia educativa de tolerância nos leva a assumir que o sentimento em relação ao outro até pode não ser o melhor, mas que se deve sempre ter o compromisso da melhor atitude com relação ao outro. Se dissermos a uma criança ou adolescente que ela não pode sentir raiva, ódio, nojo ou repulsa com relação a outra pessoa, estamos pedindo a ela que não sinta algo que provavelmente ela não pode controlar ou talvez não saiba controlar. Sentimos raiva do outro. Às vezes, repulsa e nojo. Isso é próprio do humano, como afirma Eco (2001).

Sabemos também que reprimir sentimentos não é a melhor estratégia para se educar alguém. Melhor seria reconhecer esses sentimentos, aceita-los e apesar deles se comprometer em buscar a melhor atitude na relação com o outro. Isso se expressa muito bem no fato que não preciso gostar ou amar ou aceitar alguém para respeita-lo, para trata-lo com dignidade e cordialidade. Essa estratégia que poderia ingenuamente ser considerada como uma hipocrisia legitimada é, na verdade, o processo de "entrar em um dispositivo relacional" (Charlot, 2000) urgente e necessário para tempos plurais e tão preconceituosos.

\section{BIBLIOGRAFIA:}

AUGRAS, Monique. Tolerância: os paradoxos, in: TEIXEIRA, Faustino (org.) $O$ diálogo inter-religioso como afirmação da vida, São Paulo: Paulinas, 1997, p. 77-91.

CHARLOT, Bernard. Da relação com o saber, Porto Alegre: Artes Médicas, 2000.

CORTINA, Adela. Ética civil e religião, São Paulo: Paulinas, 1997.

DE LA TAILLE, Yves. Limites: três dimensões educacionais, São Paulo: Ática, 2002. 
ECO, Umberto. Cinco escritos morais, Rio de Janeiro: Record, 2001.

MENEZES, Paulo. Tolerância e religiões, in: TEIXEIRA, Faustino (org.) $O$ diálogo inter-religioso como afirmação da vida, São Paulo: Paulinas, 1997, p. 39-54. 